\title{
Evaluation of clinical comorbidities in cognitively impaired patients with depressive symptoms
}

\author{
Rossana Maria Russo Funari ${ }^{1}$, Letícia Lessa Mansur ${ }^{1,2}$, Paulo Rogério Rosmaninho Varandas ${ }^{1}$, \\ Maria Isabel D'Avila Freitas', Wilson Jacob Filho ${ }^{1,4}$
}

\begin{abstract}
In demented patients, depressive symptoms as well as cognition and clinical comorbidities can interact and induce a complex condition of severity and handicap. Objective: The objective of this study was to evaluate the influence of depressive symptoms in cognitively impaired patients on associated clinical comorbidities in geriatric patients. Methods: One-hundred-thirty-eight (138) patients were divided into two groups: the first contained cognitively impaired patients with depressive symptoms while the second comprised cognitively impaired patients without depressive symptoms. To quantify comorbidities, the Modified CIRS Scale was used. Results: Out of the 138 patients, 52 were cognitively impaired with depressive symptoms and 86 were cognitively impaired without depressive symptoms, both having mean CDR of 1.74 (moderate dementia). The patients with depressive symptoms used more drugs ( 4.98 per patient vs. 3.45 per patient without depressive symptoms; $\mathrm{p}=0.001$ ), presented more comorbidities (3.24 per patient vs. 2.46 per patient without depressive symptoms; $\mathrm{p}=0.009$ ). However, these comorbidities were neither more severe nor more complex in the patients with depressive symptoms, with mean Comorbidity Severity Index of 1.45 in patients with and 1.37 in patients without depressive symptoms $(\mathrm{p}=$ 0.078 ) and mean Comorbidity Complexity Index of 2.41 in patients with depressive symptoms and 2.01 in those without depressive symptoms ( $\mathrm{p}=0.103$ ). Conclusion: Cognitively impaired patients with depressive symptoms had a greater absolute number of comorbidities and took more drugs although these comorbid diseases were less severe and complex than in non-depressive cognitively impaired patients.
\end{abstract}

Key words: dementia, depressive symptoms, comorbidities, depression.

\begin{abstract}
Avaliação de comorbidades clínicas em pacientes depressivos com distúrbio cognitivo.
Resumo - Em pacientes com demência, sintomas depressivos, cognição e comorbidades podem interagir resultando em uma condição de agravamento do quadro e desvantagem. Objetivo: O objetivo do estudo foi avaliar a influência de sintomas depressivos sobre as comorbidades em pacientes geriátricos com declínio cognitivo. $M e$ todos: 138 pacientes foram divididos em dois grupos: o primeiro composto de pacientes com distúrbio cognitivo associado a sintomas depressivos e o segundo de pacientes com distúrbio cognitivo sem sintomas depressivos. Para quantificar as comorbidades a Escala CIRS modificada foi utilizada. Resultados: 52 pacientes apresentavam distúrbio cognitivo com sintomas depressivos e 86 apresentavam distúrbios cognitivos sem sintomas depressivos, ambos com média de 1.74 no CDR (demência moderada). Os pacientes com sintomas depressivos usaram maior número de fármacos (4.98 / paciente com sintomas depressivos versus 3.45 / pacientes sem sintomas depressivos; $\mathrm{p}=0.001$ ), apresentaram maior número de comorbidades ( 3.24 / paciente com sintomas depressivos versus 2.46 / pacientes sem sintomas depressivos; $\mathrm{p}=0.009$ ) mas essas comorbidades não foram mais graves nem mais complexas nos pacientes depressivos: média do Índice de Gravidade das Comorbidades $=1.45$ no grupo com sintomas depressivos e 1.37 no grupo sem sintomas depressivos $(\mathrm{p}=0.078)$ e média de do Índice de Complexidade da Comorbidade com sintomas depressivos $=2.41$ no grupo com sintomas depressivos e 2.01 no grupo sem sintomas depressivos $(\mathrm{p}=0.103)$. Conclusão: Os pacientes com distúrbio cognitivo associado a sintomas depressivos apresentaram maior número absolute de comorbidades e ingeriam maior número de fármacos mas as doenças eram menos graves e complexas do que as do grupo de não depressivos.
\end{abstract}

Palavras-chave: demência, sintomas depressivos, comorbidades, depression.

${ }^{1}$ Serviço de Geriatria do Hospital das Clínicas da Faculdade de Medicina da Universidade de São Paulo. ${ }^{2}$ Departamento de Fisioterapia, Fonoaudiologia e Terapia Ocupacional. Faculdade de Medicina da USP. ${ }^{3}$ Pós-Graduação Departamento Neurologia - FMUSP. ${ }^{4}$ Departamento de Clínica Médica da Faculdade de Medicina da Universidade de São Paulo.

Rossana Maria Russo Funari - Praça Nami Jafet 55 / apto. 4183 - 042050-005 São Paulo SP - Brazil. E-mail: rossana.funari@terra.com.br Received 11/02/2007. Received in final form 11/25/2007. Accepted 11/30/2007. 
Mood alterations can affect a considerable percentage of individuals with dementia. ${ }^{1,2}$ Approximately 30 to $40 \%$ of patients with Alzheimer's disease present significant depressive symptoms ${ }^{3}$ and the prevalence of depression in vascular dementia can be even greater. ${ }^{4,5}$ Patients with depression usually present more complaints and can present greater functional compromise than those not depressed, ${ }^{6}$ although diagnosis of depression in patients with dementia remains a challenge. ${ }^{7}$ Numerous studies have demonstrated how comorbidities, frequently called psychosocial, such as agitation, aggression, pain and depression can reduce the quality of life in the patient as well as caregiver. ${ }^{8,9}$ To our knowledge, there have been no studies analyzing possible influences of depression on clinical comorbidities in ambulatory patients with dementia.

The objective of this study was to verify the impact of depression in patients with cognitive disturbances considering 1) the number, severity and complexity of comorbidities; 2) number of medications used. The study included a descriptive analysis of the two groups, regarding the most prevalent comorbidities and the type and degree of dementia.

\section{Methods}

138 patients with cognitive disturbances were selected at the Cognitive Geriatric Outpatient Unit - HC/
FMUSP from 2000 to 2007. Patients were divided into two groups: those having dementia with depressive symptoms $(\mathrm{DEM}+\mathrm{DEP})$ and those having dementia without depressive symptoms (DEM). A multidisciplinary team evaluated all patients. The criteria used to diagnose dementia were from the National Institute of Neurological and Communicative Disorders and Stroke and Alzheimer's Disease and Related Disorders Association (NINCDS-ADRDA). This classifies probable or possible Alzheimer's disease ${ }^{10}$ while the criteria of the National Institute of Neurological Disorders and Stroke and Association Internationale pour la Recherche et l'Enseignement en Neurosciences (NINDS/AIREN) classifies vascular dementia as probable or possible, ${ }^{11}$ and the Diagnostic and Statistic Manual for Mental Diseases, 4th edition (DSM-IV) assesses dementia and depressive symptoms. ${ }^{12}$ The Mini-Mental State Examination (MMSE), ${ }^{13}$ the Clinical Dementia Rating (CDR), ${ }^{14}$ the Geriatric Depression Scale (GDS 30$)^{15}$ and the modified Cumulative Illness Rating Scale (CIRS) $)^{16}$ were also applied to evaluate the degree and complexity of comorbidities.

These patients were submitted to clinical and laboratory exams, diagnosing current and previous diseases, and were questioned about the number of medications currently being taken.

Pearson's chi-square test or Fisher exact test were used

Table 1. Characteristics of the two groups studied regarding age, gender, schooling and severity of dementia.

\begin{tabular}{lccccc}
\hline & $\begin{array}{c}\text { Age (years) } \\
\text { mean (SD) }\end{array}$ & $\begin{array}{c}\text { Gender } \\
\text { Male/Female }\end{array}$ & $\begin{array}{c}\text { Schooling (years) } \\
\text { mean (SD) }\end{array}$ & $\begin{array}{c}\text { CDR } \\
\text { mean (SD) }\end{array}$ & $\begin{array}{c}\text { MMSE } \\
\text { mean (SD) }\end{array}$ \\
\hline DEM+DEP & $77.3(6.95)$ & $8 / 44$ & $4.66(5,01)$ & $1.74(0.87)$ & $15.89(7,42)$ \\
DEM & $77.2(6.69)$ & $37 / 49$ & $4.69(3.97)$ & $1.73(0.88)$ & $15.97(8.64)$ \\
\hline
\end{tabular}

DEM: dementia; DEM+DEP: dementia with depressive symptoms; CDR: clinical dementia rating scale; MMSE: mini-mental state examination; SD: standard deviation.

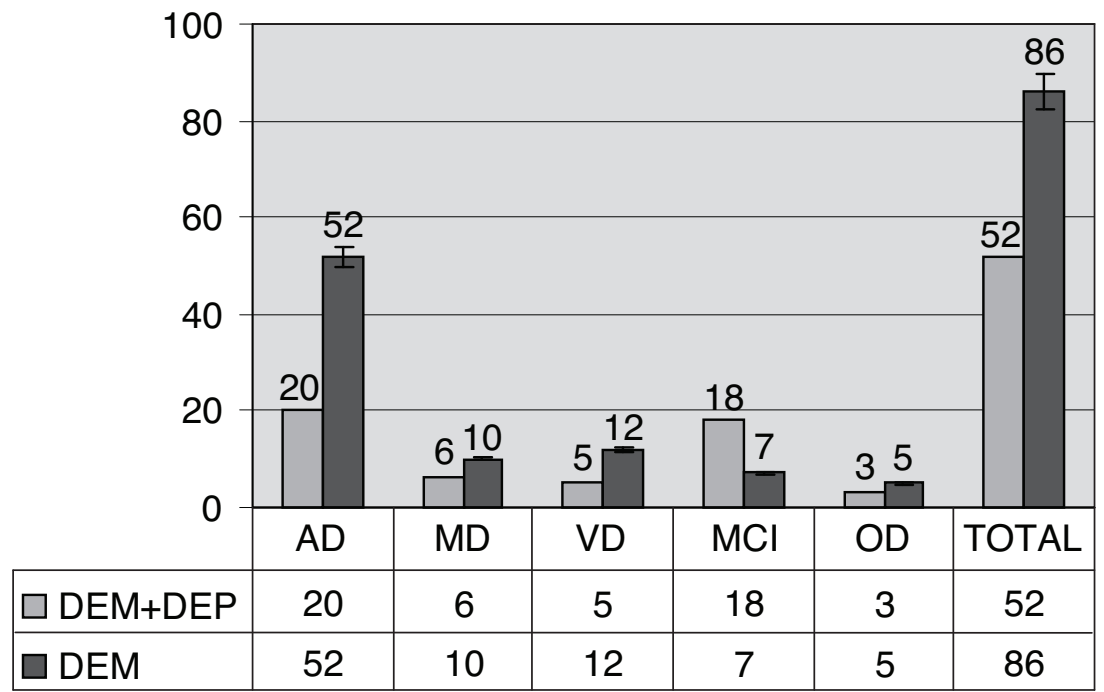

Figure 1. Diagnoses of dementias in patients with dementia and depressive symptoms, and dementia without depressive symptoms. $A D$ : Alzheimer disease; $M D$ : mixed dementia; $V D$ : vascular dementia; MCI: mild cognitive impairment; OD: other dementias; DEM+DEP: dementia with depressive symptoms; DEM: dementia without depressive symptoms . 


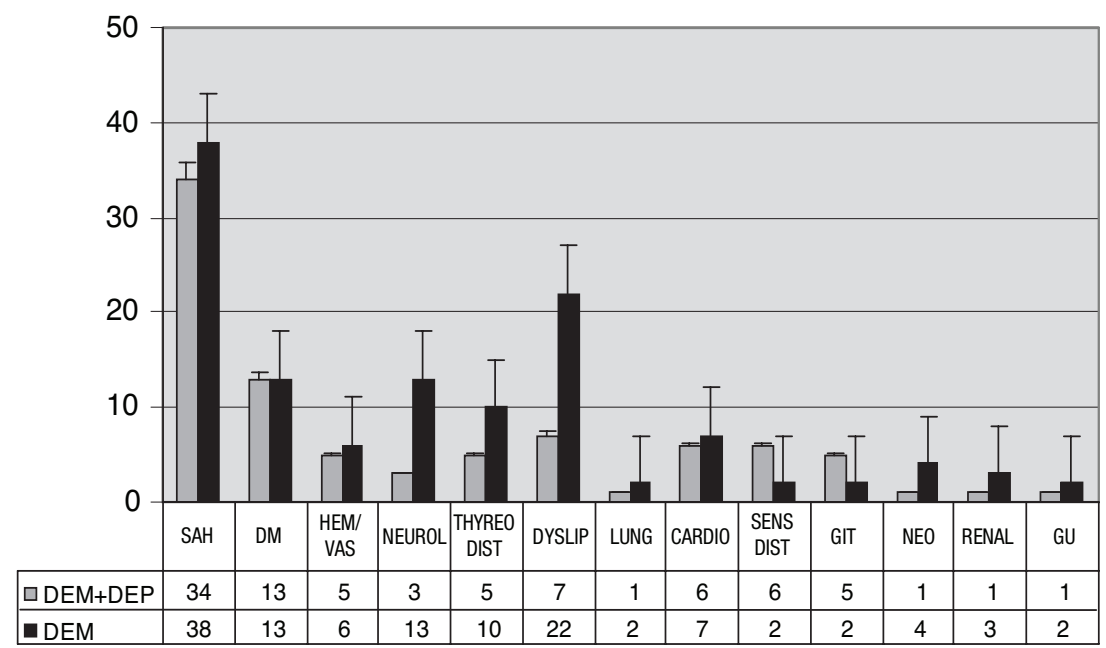

Figure 2. Most prevalent comorbidities in patients with dementia and depressive symptoms, and dementia without depressive symptoms. $S A H$, systemic arterial hypertension; DM, diabetes mellitus; HEM/VAS, hematopoietic and vascular diseasea; THYREO, diseases of thyroid; DYSLIP, dyslipidemias; LUNG, lung diseases; CARDIO, cardiopathies; SENDIST, sensorial disturbances; GIT, diseases of gastrointestinal tract; NEO, neoplasias; RENAL, renal diseases; $G U$, genito-urinary diseases.
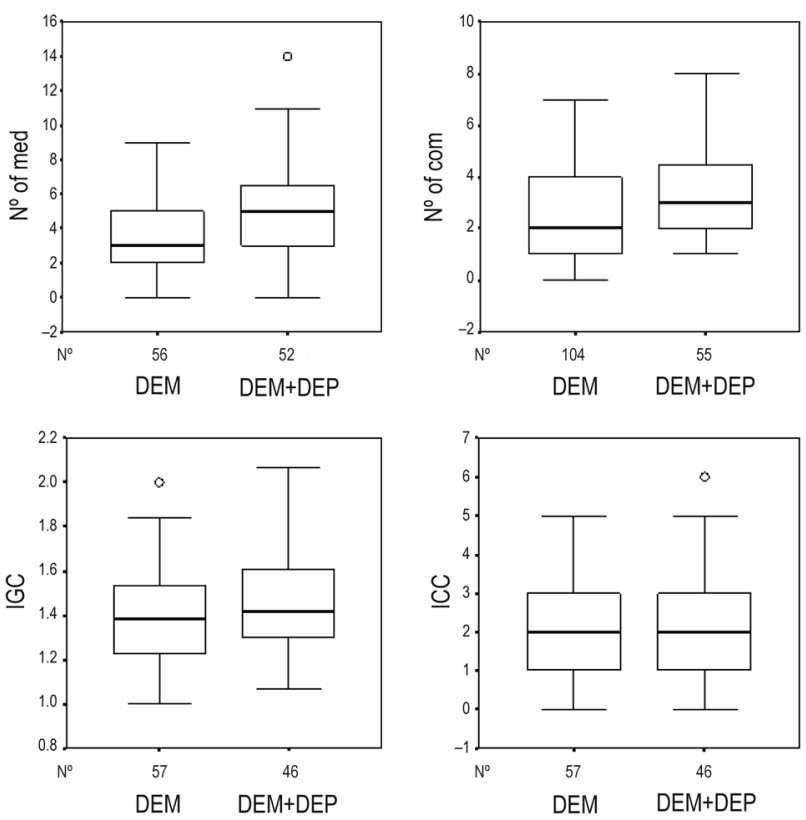

Figure 3. Box plots of the Number of medications, Number of comorbidities, comorbidity severity index, comorbidity complexity index for depressive symptoms. IGC: comorbidity severity index; ICC: comorbidity complexity index; DEM: dementia without depressive symptoms; DEM+DEP: dementia with depressive symptoms.

to compare categorical variables. Student's t test or MannWhitney test were used for quantitative variables and either Pearson or Speaman coefficients were used for correlations between variables according to the presence or absence of normal distribution of the data. ${ }^{17}$ The value of statistical significance accepted was 0.05 .

\section{Results}

Of the 138 patients, 52 belonged to the DEM+DEP group and 86 the DEM group. The characteristics of each
Table 2. Averages summary of the number of medications, number of comorbidities, comorbidity severity index, comorbidity complexity index for Dementia without depressive symptoms, and Dementia with depressive symptoms.

\begin{tabular}{lcccc}
\hline Averages summary & NM & NC & CSI & CCI \\
\hline DEM & & & & \\
$\quad \mathrm{N}$ & 86 & 104 & 87 & 87 \\
Mean & 3.45 & 2.46 & 1.37 & 2.01 \\
Median & 3.00 & 2.00 & 1.38 & 2.01 \\
Minimum & 0.00 & 0.00 & 1.00 & 0.00 \\
Maximum & 9.00 & 7.00 & 2.00 & 5.00 \\
Standard deviation & 2.23 & 1.75 & 0.22 & 1.30 \\
DEM+DEP & & & & \\
N & 52 & 55 & 46 & 46 \\
Mean & 4.98 & 3.24 & 1.45 & 2.41 \\
Median & 5.00 & 3.00 & 1.42 & 2.00 \\
Minimum & 0.00 & 1.00 & 1.07 & 0.00 \\
Maximum & 14.00 & 8.00 & 2.07 & 6.00 \\
Standard deviation & 3.05 & 1.79 & 0.25 & 1.42 \\
\hline
\end{tabular}

NM: number of medications; NC: number of comorbidities; CSI: comorbidity severity index; CCI: comorbidity complexity index; DEM: dementia without depressive symptoms; DEM+DEP: dementia with depressive symptoms.

Table 3. Inferential comparative results of average values for number of medications, number of comorbidities, comorbidity severity index, comorbidity complexity index, for dementia without depressive symptoms, and dementia with depressive symptoms.

\begin{tabular}{ll}
\hline Variables & Conclusion \\
\hline Number of medications & DEM $<$ DEM + DEP $(\mathrm{p}=0.001)$ \\
Number of comorbidities & $\mathrm{DEM}<\mathrm{DEM}+\mathrm{DEP}(\mathrm{p}=0.009)$ \\
Comorbidity severity index & $\mathrm{DEM}=\mathrm{DEM}+\mathrm{DEP}(\mathrm{p}=0.078)$ \\
Comorbidity complexity index & $\mathrm{DEM}=\mathrm{DEM}+\mathrm{DEP}(\mathrm{p}=0.103)$ \\
\hline
\end{tabular}

DEM: dementia without depressive symptoms; DEM+DEP: dementia with depressive symptoms. 
group such as age, gender, schooling and severity of dementia, are listed in Table 1. The proportion of male individuals was higher in the DEM group. The two groups presented average MMSE and CDR of 15.9 and 1.7 respectively (moderate dementia).

The diagnoses for types of dementia along with the most prevalent comorbidities are listed in Figures 1 and 2.

The most prevalent comorbidities were arterial hypertension, mellitus diabetes and dyslipidemia in both groups, with neurological disorders and dyslipidemia being more prevalent in the group without depressive symptoms, and sensorial disturbances more present in the group with depressive symptoms.

The patients with dementia and depressive symptoms took more medication: 4.98 per patient versus 3.45 medication per patient without depressive symptoms $(\mathrm{p}=0.001$ ) and presented a greater absolute number of comorbidities 3.24 versus 2.46 per patient ( $\mathrm{p}=0.009$ ), however these comorbidities were neither more severe nor more complex, according to the CIRS scales: average CSI (comorbidity severity index) with depressive symptoms was 1.45 and without depressive symptoms $1.37(\mathrm{p}=0.078)$ and average CCI (comorbidity complexity index) with depressive symptoms was 2.41 and without depressive symptoms 2.01 per patient ( $\mathrm{p}=0.103)$ (Tables 2 and 3 and Figure 3$)$.

\section{Discussion}

The findings of this study showed that when comparing two groups with very similar clinical characteristics, the group of patients with dementia associated to depressive symptoms presented a greater number of comorbidities and took a greater number of medications than non-depressive patients with dementia, although these comorbidities were neither more severe nor more complex. The majority of these illnesses did not interfere with basic activities, did not need treatment, and according to the morbidity scale used had excellent prognosis. Schubert et al., compared the profile of patients in a primary evaluation and concluded that multiple morbidities are common in the aged with or without dementia having a mean chronic disease frequency of 2.4 per patient and an average of 5.1 for medications. ${ }^{18}$ Kaup et al., compared dementia patients with depressive symptoms and depressive patients without dementia, and found a significantly positive association with greater number of comorbidities without dementia and with depressive symptoms, as well as greater physical dependency, independent of cognitive state. ${ }^{19}$ Thus, thorough diagnosis is necessary in dementia patients with depressive symptoms for correct treatment, ${ }^{20}$ although it is also important to value complaints and quantify morbidities to avoid excessive use of medication, as was seen in this study.
The most frequent comorbidities in both groups were hypertension and diabetes, while in a multi-centric study with ambulatory patients (REAL FR) cardiovascular diseases (including systemic arterial hypertension) were most frequent in patients with Alzheimer's dementia, followed by sensorial alterations and neurological disturbances. ${ }^{21}$

In the present study, the patients with depressive symptoms associated to dementia presented a greater prevalence of sensorial disturbances in relation to patients with dementia and no depressive symptoms. Perhaps these sensorial deficits (in this case visual and auditory) may contribute to the decrease in quality of life in these patients and consequently may have constituted an additional factor for the emergence of depressive symptoms in our sample.

In the literature, numerous studies have related depressive symptoms with cognitive disturbances and dementia, although it is not yet clear if the depressive symptoms contributed to the worsening of cognitive results. ${ }^{22}$ Other studies have commented that patients with depressive symptoms and dementia need more inpatient healthcare services and nursing homes, as the depressive symptoms associated with dementia can affect the course of the illness, elevating the degree of functional alteration and leading to the potential risk of being institutionalized or hospitalized. ${ }^{23}$

It would be interesting for a further study to verify whether these patients with depressive symptoms are being correctly treated with adequate doses of medications, as it is known that patients who are poorly diagnosed and treated with sub-doses have a poorer clinical evolution ${ }^{24}$ while these two groups of depressed patients without dementia could be compared and analyzed to ascertain the impact of clinical morbidities on the daily lives of these patients. Thus, this study concluded that individuals with dementia associated to depressive symptoms presented a greater absolute number of comorbidities, although these tended to be less severe and less complex than in the group without depressive symptoms. It is of the utmost importance to observe details on cognitive disturbances in association with depressive symptoms, thereby avoiding poly-pharmacy, found to be the most prevalent phenomenon in the group of patients with depressive symptoms and dementia.

Acknowledgements - This research was supported by and performed at the Geriatric Service of Hospital das Clínicas da Faculdade de Medicina da Universidade de São Paulo.

\section{References}

1. Greenwald BS, Kramer-Ginsberg E, Marin DB, et al. Dementia with coexistent major depression. Am J Psychiatry 1989;146:1472-1478. 
2. Reifler BV, Larson E, Hanley R. Coexistence of cognitive impairment and depression in geriatric outpatients. Am J Psychiatry 1982;139:623-626.

3. Lyketsos CG, Olin J. Depression in Alzheimer's disease: overview and treatment. Biol Psychiatry 2002;52:243-252.

4. Simpson S, Allen H, Tomenson B, et al. Neurological correlates of depressive symptoms in Alzheimer's disease and vascular dementia. J Affect Disord 1998;53:129-136.

5. Groves WC, Brandt J, Steinberg M et al. Vascular dementia and Alzheimer's disease: is there a difference? a comparison of symptoms by disease duration. J Neuropsychiatry Clin Neurosci 2000;12:305-315.

6. Mehta KM. Cognitive impairment, depressive symptoms, and functional decline in older people. J Am Geriatr Soc 2002;50:1045-1050.

7. Starkstein SE, Mizrahi R, Garau L. Specificity of symptoms of depression in Alzheimer disease. Am J Geriatric Psychiatry 2005;13:802-807.

8. Snow AL, Dani R, Souchek J, Sullivan G, Ashton CM, Kunik ME. Comorbid psychosocial symptoms and quality of life in patients with dementia. Am J Geriatr Psychiatry 2005;13:393-401.

9. Kunik ME, Cully JA, Snow AL, Souchek J, Sullivan G, Ashton CM. Treatable comorbid conditions and use of VA health care services among patients with dementia. Psychiatr Serv 2005;56:70-75.

10. McKhann G, Drachman D, Folstein M, et al: Clinical Diagnosis of Alzheimer's Disease: Report of the NINCDS-ADRDAwork group under the auspices of department of health and human services task force on Alzheimer's disease. Neurology 1984;34:939-44.

11. Roman GC, Tatemichi TK, Erkinjuntti T, et al: Vascular dementia: Diagnostic criteria for research studies: report of the NINDS-AIREN International Workshop. Neurology 1993;43:250-260.

12. American Psychiatric Association (DSM-IV). Diagnostic and Statistical Manual of Mental Disorders, 4th; Washington, DC: American Psychiatric Association;1994.
13. Folstein MF, Folstein SE, Mc Hugh PR. Mini-mental state. A practical method for grading the cognitive state of patients for clinician. J Psychiat Res 1975;12:189-198.

14. Morris JC. Clinical dementia rating: a reliable and valid diagnostic and staging measure for dementia of the Alzheimer type. Int Psychogeriatr 1997; 9(Suppl 1):173-176; discussion 177-8.

15. Burke WJ, Houston MJ, Boust SJ, Roccaforte WH. Use of the Geriatric Depression Scale in dementia of the Alzheimer type. J Am Geriatric Soc 1989;37: 856-860.

16. Pamelle PA, Thuras PD, Katz IR, Lawton MP. Validation of the cumulative illness rating scale in a geriatric residential population. J Am Geriatric Soc 1995;43:130-137.

17. Bussab WO, Morettin PA. Estatística básica. $5^{\circ}$ ed. São Paulo: Saraiva, 2006.

18. Schubert CC, Boustani M, Callahan CM, et al. Comordidity profile of dementia patients in primary care: are they sicker? J Am Geriatric Soc 2006;54:104-109.

19. Kaup BA, Loreck D, Gruber-Baldini AL, et al. Depression and its relationship to function and medical status, by dementia status, in nursing home admissions. Am J Geriatr Psychiatry. 2007;15:438-42.

20. Kales HC, Chen P, Blow FC, Welsh DE, Mellow AM. Rates of clinical depression diagnosis, functional impairment, and nursing home placement in coexisting dementia and depression. Am J Geriatr Psychiatry 2005;13:441-449.

21. Artaz MA, Boddaert J, Hériche-Taillandier E, Dieudonné B, Verny M; le groupe REAL.FR. Medical comorbidity in Alzheimer's disease: baseline characteristics of the REAL.FR Cohort. Rev Med Interne. 27:91-97.

22. Ganguli M, Du Y, Dodge HH, Ratcliff GG, Chang CC. Depressive symptoms and cognitive decline in late life: a prospective epidemiological study. Arch Gen Psychiatry. 2006;63:153-160.

23. Kales HC, Blow FC, Copeland LA, et al: Healthcare utilization by older patients with coexisting dementia and depression. Am J Psychiatry 1999;156:550-556.

24. Lyketsos CG, Del Campo L, Steinberg M, Miles Q. Treating depression in Alzheimer disease 2003;60:737-746. 